\title{
Comunicação \\ Levantamento de moscas-das-frutas e seus parasitoides em citros, no município de Viçosa, Minas Gerais
}

\author{
Daniel Lucas Magalhães Machado ${ }^{1}$, Tiago Barbosa Struiving ${ }^{1}$, Dierlei dos Santos ${ }^{2}$, \\ Silvana Aparecida da Silva Souza ${ }^{2}$ Dalmo Lopes de Siqueira ${ }^{3}$
}

\section{RESUMO}

As moscas-das-frutas são responsáveis por grandes perdas em fruteiras comerciais no Brasil, por isso é fundamental conhecer as espécies predominantes na região. Objetivou-se com este trabalho estudar a ocorrência de moscasdas-frutas (Diptera: Tephritidae) e seus parasitoides em laranjas doces (Citrus sinensis L. Osbeck), tangerina Poncã (Citrus reticulata Blanco) e mexerica Rio (Citrus deliciosa Ten), no município de Viçosa, Minas Gerais. Os frutos foram coletados em abril de 2008. No laboratório eles foram acondicionados em caixas plásticas contendo areia umedecida e em ambiente controlado para obtenção dos pupários, que foram contados, acondicionados em frascos de vidro com areia fina e mantidos em estufa até a emergência dos adultos. Somente uma espécie de mosca-das-frutas (Anastrepha fraterculus (Wiedemann, 1830) e uma de parasitoide (Doryctobracon brasiliensis Szépligeti) foram identificadas. Dentre as variedades, a laranja doce Baianinha apresentou o maior índice de infestação, e os menores foram atribuídos à mexerica Rio e à tangerina Poncã.

Palavras-chave: Tephritidae, Anastrepha fraterculus, infestação.

\section{ABSTRACT}

\section{Survey of fruit-flies and their parasitoids in citrus in Viçosa, Minas Gerais}

Fruit flies are responsible for large losses in commercial orchards in Brazil, thus, it is important to know the predominant species in the region. The objective of this study was to study the occurrence of fruit flies (Diptera: Tephritoidae) and of their parasitoids in sweet orange (Citrus sinensis L. Osbeck), 'Poncã' mandarin (Citrus reticulate Blanco) and 'Rio' tangerine (Citrus deliciosa Ten), in Viçosa, Minas Gerais. The fruits were collected in April 2008. In the laboratory, the fruits were stored in plastic boxes containing moist sand in a controlled environment, to obtain pupae. Then, the pupae were counted, placed in glass bottles with fine sand and kept in an oven until adult emergence. Only one species of fruit fly (Anastrepha fraterculus (Wiedemann, 1830) and one species of parasitoid (Doryctobracon brasiliensis Szépligeti) were identified. Among the varieties, the sweet orange 'Baianinha' showed the highest rate of infection and the lower were assigned to the 'Rio' tangerine and 'Poncã' mandarin.

Key words: Tephritoidae, Anastrepha fraterculus, infestation.

\footnotetext{
Recebido para publicação em 09/05/2011 e aprovado em 29/08/2012.

'Graduandos em Agronomia. Universidade Federal de Viçosa, Campus Viçosa, Avenida Peter Henry Rolfs, s/n, 36570-000, Viçosa, Minas Gerais, Brasil. Bolsistas do CNPq. danielm.machado@ufv.br (autor correspondente); struiving@hotmail.com

${ }^{2}$ Engenheiros-Agrônomos, Doutores. Departamento de Fitotecnia, Universidade Federal de Viçosa, Campus Viçosa, Avenida Peter Henry Rolfs, s/n, 36570-000, Viçosa, Minas Gerais, Brasil. dierlei@vicosa.ufv.br; silvana.diptera@gmail.com

${ }^{3}$ Engenheiro-Agrônomo, Doutor. Departamento de Fitotecnia, Universidade Federal de Viçosa, Campus Viçosa, Avenida Peter Henry Rolfs, s/n, 36570-000, Viçosa, Minas Gerais, Brasil.siqueira@ufv.br
} 


\section{INTRODUÇÃO}

O levantamento das espécies de moscas-das-frutas, especialmente as pertencentes à família Tephritidae, suas plantas hospedeiras e seus parasitoides são fundamentais para melhor compreensão da bioecologia desse grupo de insetos, dada sua importância econômica para a fruticultura mundial (Zilli \& Garcia, 2010).

As moscas-das-frutas são responsáveis por grandes perdas em fruteiras comerciais no Brasil, sendo os prejuízos decorrentes tanto da oviposição quanto da alimentação das larvas, que destroem a polpa dos frutos, provocando a maturação acelerada e a queda prematura (AguiarMenezes et al., 2004).

No Brasil, as espécies de moscas-das-frutas de importância econômica basicamente são Anastrepha spp. e Ceratitis capitata (Wiedemann). As diversas espécies de Anastrepha spp. são nativas do continente americano, enquanto $C$. capitata é a única espécie de origem africana presente no nosso País (Malavasi et al., 2000).

A incidência de moscas-das-frutas em citros é um fator preocupante todos os anos, causando aumento nos custos de produção, em razão das frequentes aplicações de inseticidas para o controle das perdas na produção (Nora et al., 2000). Nos últimos anos, a densidade populacional das moscas vem aumentando nos pólos de fruticultura do Brasil (Barreto, 2010). Esse crescimento deve-se principalmente à aplicação indiscriminada de agrotóxicos, que afeta a população de inimigos naturais da praga nos pomares, o crescimento da área plantada e a diversificação de hospedeiros (Carvalho, 2005).

A citricultura está crescendo na Zona da Mata mineira e não existem informações sobre quais espécies de moscas-das-frutas atacam os citros na região, sendo esse conhecimento importante para estabelecer estratégias de manejo dessa praga. Neste trabalho, procurou-se levantar a população de moscas-das-frutas e a presença de parasitoides, visando identificar as espécies de ocorrência na cidade de Viçosa, Minas Gerais.

\section{MATERIAL E MÉTODOS}

$\mathrm{O}$ estudo foi desenvolvido na Universidade Federal de Viçosa, MG, no Departamento de Fitotecnia, em abril de 2008.

As avaliações foram realizadas em frutos das variedades de laranjas doces (Citrus sinensis L. Osbeck): Kona, Serra d’Água, Baianinha, Pêra Rio, Campista, Lima e Kahilily White; tangerina Poncã (Citrus reticulata Blanco) e mexerica Rio (Citrus deliciosa Ten), oriundas da coleção de citros da UFV, Viçosa.

No pomar, frutos maduros e apresentando boas condições de conservação foram coletados aleatoriamente de 10 plantas por variedade, sendo seis frutos por planta, totalizando 60 frutos em cada variedade.
No laboratório os frutos foram lavados e desinfetados com solução de hipoclorito de sódio a 10\%, secados com papel toalha, pesados e colocados em caixas plásticas ( 40 x 30 x $15 \mathrm{~cm}$ ). No interior das caixas, havia uma camada de $4 \mathrm{~cm}$ de espessura de areia peneirada e umedecida, como substrato para o empupamento das larvas. Em cada caixa foram colocados 15 frutos cobertos com tecido tipo voile, o qual foi preso pelas bordas com uma liga de borracha, de modo a revestir externamente as laterais da caixa.

As caixas contendo os frutos foram mantidas em câmara com temperatura controlada a $25 \pm 3{ }^{\circ} \mathrm{C}, 80 \%$ UR e 12 horas de fotofase, por um período total de 34 dias, para a saída das larvas do interior dos frutos para pupação. As caixas foram inspecionadas diariamente, para manter a umidade do substrato.

A retirada dos pupários iniciou-se a partir do $14^{\circ}$ dia, com auxílio de uma peneira (malha de $1,0 \mathrm{~mm}^{2}$ ), e foi repetida duas vezes com intervalo de 10 dias, totalizando três coletas até a total decomposição dos frutos. As pupas foram quantificadas e acondicionadas em frascos de vidro transparentes, devidamente etiquetados, contendo no seu interior areia fina, umedecida a cada dois dias, para facilitar a hidratação das pupas e a emergência dos adultos.

Diariamente, foram feitas contagens do número de adultos emergidos até a emergência de todas as pupas dos frascos. Após, as moscas-das-frutas e os parasitoides que emergiram foram acondicionados em recipientes de vidro, contendo álcool 70\%, sendo posteriormente sexados e identificados. Para identificação das espécies de Anastrepha, os acúleos das fêmeas foram extrovertidos e examinados ao microscópio óptico (40x), conforme Zucchi (2000b). Para os parasitoides, a identificação foi feita por meio da análise das mandíbulas, propódeo, nervação alar e das tíbias, conforme Canal \& Zucchi (2000).

As variáveis calculadas foram: número total de pupários, número total de adultos emergidos, número total de parasitoides emergidos, percentual de emergência de adultos e índice de infestação de frutos (I.F.), dado pelo número médio de pupários por fruto e pelo número médio de pupários por quilograma de fruto.

\section{RESULTADOS E DISCUSSÃO}

Coletou-se, nas nove variedades e nos dois períodos de avaliação, um total de 603 pupários, e desse a emergência de adultos foi de $21,89 \%$. Na terceira avaliação, nenhum pupário foi encontrado (Tabela 1).

De todos os adultos emergidos, identificaram-se apenas três parasitoides da espécie Doryctobracon brasiliensis, todos em frutos de mexerica Rio, o que pode ser explicado, segundo Aguiar-Menezes \& Menezes (2000), pelo menor tamanho do fruto e pela espessura da polpa. O restante dos adultos foi de moscas-das-frutas 
da espécie Anastrepha fraterculus. Essa é uma característica própria de cada região e das variedades em estudo. A predominância de $A$. fraterculus também foi verificada por Pirovani et al. (2010) estudando a diversidade de espécies de Tefrítideos, seus parasitoides e hospedeiros em Viçosa-MG. Outros autores, nas regiões Sul e Sudeste do Brasil, verificaram o mesmo, como Chiaradia et al. (2004) em Santa Catarina, Souza Filho et al. (1998) e Raga et al. (2004) em São Paulo, Aguiar-Menezes \& Menezes (2000) no Rio de Janeiro e Silva (2005) no Rio Grande do Sul.

O número médio de pupários de A. fraterculus por fruto e por quilograma de fruto variou conforme a variedade de citros, e as variedades com maior número de pupários foram Baianinha (129), Serra d'Água (118) e Kahilily White (102), enquanto a mexerica Rio e a tangerina Poncã apresentaram apenas seis e sete, respectivamente (Tabela 1). Quanto aos dados da percentagem de emergência de adultos, esses variaram entre $0 \%$ e $50 \%$ (Tabela 1), tendo a maioria dos valores se assemelhado ao encontrado por Pirovani et al. (2010), de 18,19\%, em laranjas doces (Citrus sinensis), em Viçosa-MG.

Os índices médios de infestação foram 1,12 pupário/ fruto e 7,09 pupários/kg de fruto. As laranjas doces fo- ram às variedades cítricas mais susceptíveis ao ataque das moscas-das-frutas. Em amostras isoladas, os maiores índices de infestação foram apresentados pela Baianinha (2,15 pupários/fruto e 11,25 pupários/kg de fruto) e Serra d’Água (1,97 pupário fruto e 13,24 pupários/ $\mathrm{kg}$ de fruto), e os menores foram atribuídos à mexerica Rio ( 0,10 pupário/fruto e 1,11 pupário/kg de fruto) e à tangerina Poncã (0,12 pupário/fruto e 0,77 pupário/kg de fruto) (Tabela 2). A menor infestação nas últimas pode ser devido à alta acidez dos frutos no momento da colheita, visto que são variedades de maturação mais tardia. Comparando esses resultados com os obtidos por Souza Filho et al. (1998), pode-se concluir que a mexerica Rio e a tangerina Poncã apresentaram índices de infestação considerados normal e baixo, respectivamente. Esse autor relata índice de infestação muito semelhante em mexerica Rio, com 0,05 pupário/fruto e 1,01 pupário/kg de fruto, e índice de infestação superior em tangerina Poncã, com 3,43 pupários/fruto e 31,01 pupários/kg de fruto no Estado de São Paulo. Outros autores também verificaram menor infestação de moscas-das-frutas em tangerinas, comparadas às laranjas, como Raga et al. (2004) e Souza et al. (2008).

Tabela 1. Número de pupários e adultos por coleta, número total de pupários, número total de adultos emergidos e percentual de emergência de adultos de moscas-das-frutas encontrados em variedades de citros em Viçosa-MG

\begin{tabular}{|c|c|c|c|c|c|c|c|}
\hline \multirow{3}{*}{ Variedades } & \multicolumn{4}{|c|}{ Coletas } & \multicolumn{3}{|c|}{ Emergência } \\
\hline & \multicolumn{2}{|c|}{$\mathbf{1}^{\mathrm{o}}$} & \multicolumn{2}{|c|}{$2^{\circ}$} & \multirow{2}{*}{$\begin{array}{c}\text { Pupários } \\
\text { (total) }\end{array}$} & \multirow{2}{*}{$\frac{\text { Adultos }}{\text { (total) }}$} & \multirow{2}{*}{$\frac{\text { Adultos }}{(\%)}$} \\
\hline & Pupários & Adultos & Pupários & Adultos & & & \\
\hline Kona & 96 & 14 & 3 & 1 & 99 & 15 & 15,15 \\
\hline Serra d'Água & 96 & 23 & 22 & 1 & 118 & 24 & 20,33 \\
\hline Baianinha & 115 & 25 & 14 & 0 & 129 & 25 & 11,63 \\
\hline Pêra Rio & 57 & 7 & 13 & 5 & 70 & 12 & 17,14 \\
\hline Campista & 28 & 9 & 2 & 2 & 30 & 11 & 36,67 \\
\hline Lima & 34 & 17 & 8 & 4 & 42 & 21 & 50,00 \\
\hline Kahilily White & 85 & 17 & 17 & 2 & 102 & 19 & 18,63 \\
\hline M. Rio & 6 & 3 & 0 & 0 & 6 & 3 & 50,00 \\
\hline T. Poncã & 3 & 0 & 4 & 0 & 7 & 0 & 0,00 \\
\hline Total & 520 & 115 & 83 & 17 & 603 & 132 & 21,89 \\
\hline
\end{tabular}

Tabela 2. Massas média e total dos frutos $(n=60)$, número médio de pupários por fruto e número médio de pupários por quilograma de fruto em diferentes variedades de citros em Viçosa-MG

\begin{tabular}{lccccc}
\hline Variedades & Massa Média $(\mathbf{g})$ & Massa Total $(\mathbf{k g})$ & Pupário/Fruto & Pupário/Quilo & Fruto/Pupário \\
\hline Kona & 168,4 & 10,103 & 1,65 & 9,80 & 0,6 \\
Serra d'Água & 148,6 & 8,915 & 1,97 & 13,24 & 0,5 \\
Baianinha & 191,0 & 11,463 & 2,15 & 11,25 & 0,5 \\
Pêra Rio & 128,8 & 7,725 & 1,17 & 9,06 & 0,9 \\
Campista & 131,3 & 7,878 & 0,50 & 3,81 & 2,0 \\
Lima & 113,3 & 6,798 & 0,70 & 6,18 & 1,4 \\
Kahilily White & 199,0 & 11,943 & 1,70 & 8,54 & 0,6 \\
Mexerica Rio & 89,9 & 5,393 & 0,10 & 1,11 & 10,0 \\
Tangerina Poncã & 150,9 & 9,053 & 0,12 & 0,77 & 8,6 \\
\hline
\end{tabular}




\section{CONCLUSÕES}

Em Viçosa, MG, somente a espécie de mosca das frutas Anastrepha fraterculus foi encontrada, observandose, também, a presença do parasitoide Doryctobracon brasiliensis.

As laranjas doces foram mais suscetíveis à infestação de moscas-das-frutas em Viçosa-MG, quando comparadas com a tangerina Poncã e com a mexerica Rio.

\section{REFERÊNCIAS}

Aguiar-Menezes EL \& Menezes EB (2000) Rio de Janeiro. In: Malavasi A \& Zucchi RA (Eds.) Moscas-das-frutas de importância econômica no Brasil: conhecimento básico e aplicado. Ribeirão Preto, Holos. p.119-126.

Aguiar-Menezes EL, Ferrara FAA \& Menezes EB (2004) Moscasdas-frutas. In: Cassino PCR \& Rodrigues WC (Eds.) Citricultura Fluminense: principais pragas e seus inimigos naturais. Seropédica, Universidade Rural. p.67-84.

Barreto NTR (2010) Moscas-das-frutas (Diptera: Tephritidae) e seus parasitóides em goiaba e acerola nos tabuleiros litorâneos, Parnaíba, Piauí, Brasil. Dissertação de Mestrado. Universidade Federal do Piauí, Teresina. 88p.

Canal NAD \& Zucchi RA (2000) Parasitóides - Braconidae. In: Malavasi A \& Zucchi RA (Eds.) Moscas das frutas de importância econômica do Brasil: conhecimento básico e aplicado. Ribeirão Preto, Holos. p.119-126.

Carvalho RS (2005) Metodologia para monitoramento populacional de moscas-das-frutas em pomares comerciais. Cruz das Almas, Embrapa Mandioca e Fruticultura Tropical. 17p. (Circular Técnica, $\mathrm{n}^{\circ} 75$ ).

Chiaradia LA, Milanez JM \& Dittrich R (2004) Flutuação populacional de moscas-das-frutas em pomares de citros no oeste de Santa Catarina, Brasil. Ciência Rural, 34:337-343.

Malavasi A, Zucchi RA \& Sugayama RL (2000) Biogeografia. In: Malavasi A \& Zucchi RA (Eds.) Moscas-das-frutas de importância econômica no Brasil: conhecimento básico e aplicado. Ribeirão Preto, Holos. p.93-98.

Nora I, Hickel ER \& Prando HF (2000) Moscas-das-frutas nos Estados Brasileiros: Santa Catarina. In: Malavasi A \& Souza Filho MF (Eds.) Moscas-das-frutas: a importância relativa das espécies em citros do Estado de São Paulo. Ribeirão Preto, Holos. p.271-275.

Pirovani VD, Martins DS, Souza SAS, Uramoto K \& Ferreira PSF (2010) Moscas-das-frutas (Diptera: Tephritidae), seus parasitoides e hospedeiros em Viçosa, Zona da mata mineira. Arquivos do Instituto Biológico, 77:727-733.

Raga A, Prestes DAO, Souza Filho MF, Sato ME, Siloto RC, Guimarães JÁ \& Zucchi RA (2004) Fruit fly (Diptera: Tephritoidea) infestation in citrus in the States of São Paulo, Brazil. Neotropical Entomology, 33:85-89.

Silva FF (2005) Espécies de moscas frugívoras (Diptera: Tephritidae e Lonchaeidae), quantificação de danos e avaliação de medidas para o seu manejo em pomares orgânicos de citros. Tese de Doutorado. Universidade Federal do Rio Grande do Sul, Porto Alegre. 152p.

Souza Filho MF, Raga A \& Zucchi RA (1998) Infestação de moscas-das-frutas (Diptera, Tephritidae) em frutos cítricos no Estado de São Paulo. In: Congresso Brasileiro de Entomologia, Rio de Janeiro. Anais, SEB. p.475.
Souza JF, Souza SAS, Aguiar-Menezes EL, Ferrara FAA, Nascimento SA, Rodrigues WC \& Cassino PCR (2008) Diversidade de moscas-das-frutas em pomares de citros no município de Araruama, RJ. Ciência Rural, 38:518-521.

Zilli GN \& Garcia FRM (2010) Análise faunística e flutuação populacional de moscas-das-frutas (Diptera, Tephritidae) em pomar de Citrus sinensis no município de Chapecó, Santa Catarina. Biodiversidade Pampeana, 8:39-45.

Zucchi RA (2000b) Taxonomia. In: Malavasi RA (Ed.) Moscasdas-frutas de importância econômica no Brasil: Conhecimento básico e aplicado. São Paulo, Holos. p.13-21. 